\title{
Phenotypic and Genotypic Characterization of Nosocomial Isolates of Staphylococcus aureus with Reference to Methicillin Resistance
}

\author{
Mounir M Salem-Bekhit ${ }^{1,2}$ \\ ${ }^{1}$ Kayyali Chair for Pharmaceutical Industries, Department of Pharmaceutics, College of Pharmacy, King Saud University, PO \\ Box 2457, Riyadh 11451, Saudi Arabia, '2Department of Microbiology and Immunology, Faculty of Pharmacy, Al-Azhar \\ University, Cairo, Egypt
}

*For correspondence: Email: mounirmsalem@yahoo.com, mbekhet@ksu.edu.sa; Tel: +966 501783166

\begin{abstract}
Purpose: To investigate the occurrence, species prevalence, antibacterial resistance, and molecular characteristics of $S$. aureus isolates from different wards located in a university hospital. Methods: A total of one hundred and fifty $S$. aureus isolates were recovered from various clinical specimens. The isolates were tested phenotypically by conventional methods and genotypically by polymease chain reaction (PCR) for direct detection of femB and mecA genes.

Results: Thirty one isolates (20.7\%) of these were identified as methicillin-resistant Staphylococcus aureus (MRSA) by oxacillin agar screen test and 124 (82.7\%) of the isolates were $\beta$-lactamase producers. The prevalence of MRSA strains among S. aureus isolates was $20.7 \%$. The overall resistance of MRSA to a variety of antibiotics tested was linezolid, $48.7 \%$; ciprofloxacin, $15.3 \%$; sulfamethoxazole/trimethoprim (TMS), $14.0 \%$; gentamicin, $12.7 \%$; and rifampicin, $6.7 \%$. All MRSA isolates were positive for femB and mecA genes; one MSSA carried mecA gene.

Conclusion: Since S. aureus isolates are commonly associated with wound infections, skin and soft tissue infections and blood stream infections, glycopeptides, mupirocin, and quinupristin/dalfopristin $(Q / D)$ would be the most effective antibiotics for the treatment of MRSA infections.
\end{abstract}

Keywords: Staphylococcus aureus, mecA, femB, Antibiotics, Staphylococcal infections, Methicillin resistance

Tropical Journal of Pharmaceutical Research is indexed by Science Citation Index (SciSearch), Scopus, International Pharmaceutical Abstract, Chemical Abstracts, Embase, Index Copernicus, EBSCO, African Index Medicus, JournalSeek, Journal Citation Reports/Science Edition, Directory of Open Access Journals (DOAJ), African Journal Online, Bioline International, Open-J-Gate and Pharmacy Abstracts

\section{INTRODUCTION}

S. aureus is a major cause of serious hospital and community-acquired infections associated with morbidity and mortality rates with rapid development of resistance [1]. MRSA is one of the highest ranking pathogens worldwide and represents a real challenge to the clinical practice with significant public health concern [2]. The global problem of increasing trend in antimicrobial resistance is particularly pressing in the developing countries, where the MRSA is often the severe casual agent in hospitalacquired infections [3]. The main bacterial species has been associated with a variety of diseases, such as skin and soft tissue infections, endovascular infections, pneumonia, endocarditis and septic shock [4]. These strains show resistance to a wide range of antimicrobials including vancomycin, the drug of last resort for MRSA infections [5].

The introduction of methicillin in 1960s had an important impact on the treatment of infections 
caused by penicillinase producing $S$. aureus [6]. Shortly later, MRSA strains with a changed penicillin binding protein (PBP) appeared and spread worldwide [7]. Such resistance mechanism is due to production of a modified PBP2 (PBP2a) with low affinity to $\beta$-lactam antibiotics as a result of the acquisition of a mecA gene [8]. It can be difficult to detect MRSA because of the heterogeneous nature of methicillin resistance. The mecA gene is highly conserved among the Staphylococcal species and consequently, the detection of this gene by the polymerase chain reaction (PCR) is considered as the "gold standard" for the detection of methicillin resistance in Staphylococci [9]. The existence of the mecA gene in $S$. aureus characterizes methicillin resistance, whereas the absence of the gene indicates methicillin susceptibility [10]. More over different studies have shown that fem (factors essential for methicillin resistance) or the auxiliary genes like fem $A / B / X$ in addition to $\operatorname{mec} A$ are also significant in the expression of methicillin resistance [11].

A significant increase of MRSA in Egyptian hospitals has been reported $[12,13,14]$. However, regional differences in the epidemiologic factors of MRSA appear to be significant. Varying prevalence rates of MRSA were reported from different areas in Egypt, with figures from more than $16 \%$ [15] to as high as $61.45 \%$ [16].

The treatment of severe infections caused by some epidemic strains of MRSA is much more difficult and expensive than with MSSA because most of MRSA strains are resistant to multiple antibiotics [6]. Accurate and rapid identification of MRSA and their antimicrobial susceptibility profile is essential for the selection of appropriate therapy [17]. Therefore, it is clinically crucial to determine quickly whether $S$. aureus isolates are methicillin resistant or not, as this is very significant for both treatment and requires extensive hygienic precautions to limit the spread of such strains. The present study was carried out to determine the prevalence of $S$. aureus and MRSA in a university hospital and to determine the prevalence of $\beta$-lactamase production and susceptibility pattern to various antimicrobial agents used in treatment of MRSA infections, including some new drugs.

\section{EXPERIMENTAL}

\section{Clinical specimens}

Clinical specimens were collected from 18083 patients admitted in various departments during February to September 2012 at Tanta University hospital (TUH) (1100-bed tertiary care teaching hospital). The samples represented; wound discharge, blood, body fluids aspirates, urine, faeces, sputum, swabs from nose, throat, ear and genital areas. In some patients, MRSA was isolated from multiple culture sites but a single representative isolate was analyzed. Samples were inserted in Stuart's transport medium (SSI) and delivered to the laboratory within one hour.

\section{Identification of $S$. aureus}

The specimen of each patient were cultured into a $10 \mathrm{ml}$ nutrient broth and incubated overnight at $37{ }^{\circ} \mathrm{C}$. Following overnight incubation, $10 \mu \mathrm{l}$ of the broth was plated on agar plates containing horse blood $5 \% \mathrm{v} / \mathrm{v}$ and mannitol salt agar (MSA) media then incubated at $37{ }^{\circ} \mathrm{C}$ for $24 \mathrm{~h}$. The agar plates were examined after incubation for 2 days for typical staphylococcal colonies. Identification of the developed colonies was depended on morphology and biochemical reactions according to standard laboratory criteria [18]. Phenotypic characterization to the species level was performed using the API system for the identification of $S$. aureus (Biomerieux, France).

\section{Antibacterial susceptibility studies}

The $S$. aureus isolates were subjected to susceptibility testing using disc diffusion technique according to the Clinical and Laboratory Standards Institute (CLSI) [19] guidelines with quality controls. The antimicrobials tested included trimethoprimsulphamethoxazole TMS $(25 \mu \mathrm{g})$; gentamycin $(10 \mu \mathrm{g})$; rifampicin $(30 \mu \mathrm{g})$; ciprofloxacin $(5 \mu \mathrm{g})$; vancomycin $(30 \mu \mathrm{g})$; teicoplanin $(30 \mu \mathrm{g}) ; \mathrm{Q} / \mathrm{D}(15$ $\mu \mathrm{g})$; mupirocin $(200 \mu \mathrm{g})$ and linezolid $(30 \mu \mathrm{g})$.

\section{Detection of MRSA}

The MRSA detection was carried out according to CLSI guidelines with Oxacillin agar screen test [19] using Mueller-Hinton agar MHA (Difco Laboratories, Detroit, Mich.) containing $4 \% \mathrm{NaCl}$ and $6 \mu \mathrm{g} / \mathrm{ml}$ oxacillin. Standard inocula were prepared from overnight culture in Mueller Hinton Broth MHB (Difco Laboratories, Detroit, Mich.) after matching the $0.5 \mathrm{McF}$ arland $\left(10^{5} \mathrm{CFU} / \mathrm{ml}\right)$ and further dilution so as final inoculum is approximately $10^{4} \mathrm{CFU} / \mathrm{ml}$. The oxacillin agar plates were inoculated $10 \mu \mathrm{L}$ of the broth. The plates were incubated at $35{ }^{\circ} \mathrm{C}$ for $48 \mathrm{~h}$. The MRSA positive and negative standard reference controls were concurrently used. The growth of one or more colonies per spot indicates positive test. Indistinct results were confirmed by the MIC determined with oxacillin by agar dilution method. 
All isolates were confirmed by PCR for detection of the $m e c A-f e m B$ gene.

\section{Microorganisms}

The reference strains S. aureus ATCC 29213 (methicillin sensitive), S. aureus ATCC 23591 (MRSA), Haemophillus influenza R368 ( $\beta-$ lactamase positive), and $H$. influenza ATCC 49247 ( $\beta$-lactamase negative) were used in the study. All the test organisms were maintained at $70{ }^{\circ} \mathrm{C}$ in nutrient broth medium.

\section{Minimum inhibitory concentration (MIC)}

The agar dilution method was used according to the CLSI recommendations [19]. Two-fold serial dilutions of antimicrobial agent were prepared in MHA medium. Standardized suspensions of the test organisms (equivalent to the $0.5 \mathrm{McF}$ arland) were prepared from overnight cultures in MHB. The test organisms were inoculated in approximately $10^{4} \mathrm{CFU} / \mathrm{ml}$. The plates were incubated at $37{ }^{\circ} \mathrm{C}$ for $24 \mathrm{~h}$. Reference quality control organisms were used. The following antibacterial agents were used with the respective concentration range in $\mu \mathrm{g} / \mathrm{ml}$ : rifampicin (0.00125 - 64), trimethoprimsulphamethoxazole TMS $(0.124$ - 512), gentamicin (0.06 - 512), ciprofloxacin (0.124 $512)$, vancomycin $(0.125$ - 64), linezolid (0.25 $32), Q / D(0.03$ - 16), and mupirocin (0.03 - 64).

\section{Beta-lactamase detection}

The ability of the isolates to produce $\beta$-lactamase was detected with nitrocefin (Oxoid) according to the manufacturer's instructions. The test organisms were first inoculated onto tryptic soy agar containing $0.5 \mu \mathrm{g} / \mathrm{ml}$ ampicillin as inducer. Nitrocefin solution $(5 \mu \mathrm{l})$ was dropped onto a loopful of pure overnight growth placed on a filter membrane. The development of a red colour within 60 s indicated a positive result.

\section{Multiplex PCR}

DNA extraction: Bacterial DNA was extracted from overnight cultures of $S$. aureus at $37^{\circ} \mathrm{C}$ in tryptic soy broth according to (Hexadecyl trimethylammonium bromide- Sodium Chloride) CTAB- $\mathrm{NaCl}$ method [20]. The quality of isolated DNA was determined visually by horizontal gel electrophoresis in $1 \%(\mathrm{w} / \mathrm{v})$ agarose gel and met the requirements for experimental use.

PCR amplification: According to the basis of the DNA sequences of the mecA and fem $B$ genes, the oligonucleotides in Table 1 were employed for the detection of susceptible genes. The primers used for amplification of the genes were designed as published by [21].

PCR amplification was carried out on purified genomic DNA extracted from clinical isolates. Each DNA sample $(10 \mu \mathrm{l})$ was added to $90 \mathrm{ml}$ of the PCR mixture consisting of $10 x$ Buffer, $25 \mathrm{mM}$ of $\mathrm{MgCl} 2,2.5 \mathrm{U}$ of Taq polymerase, $0.25 \mathrm{mM}$ of dNTP and $0.5 \mu \mathrm{M}$ of each primer; mecA and femB. Initial denaturation was carried out for 3 mins at $92{ }^{\circ} \mathrm{C}$ followed by 30 cycles of amplification (denaturation at $92{ }^{\circ} \mathrm{C}$ for $1 \mathrm{~min}$, annealing at $56^{\circ} \mathrm{C}$ for $1 \mathrm{~min}$, and extension at 72 ${ }^{\circ} \mathrm{C}$ for 1 min with an increment of 2 secs per cycle). The final extension was performed at 72 ${ }^{\circ} \mathrm{C}$ for $3 \mathrm{~min}$.

Amplification was carried out in a Bio-Rad thermal cycler. After amplification, $17 \mu \mathrm{l}$ of PCR sample was loaded on a $1 \%(\mathrm{w} / \mathrm{v})$ agarose gel (Bioline, London, UK) containing $0.5 \mathrm{~g} / \mathrm{ml}$ ethidium bromide and run in a horizontal gel electrophoresis unit (Mini-Sub DNA cell, BioRad). The running buffer was TAE [40 mM Tris, $20 \mathrm{mM}$ acetic acid, $1 \mathrm{mM}$ ethylene diamine tetra-acetic acid (EDTA), pH 8.0]. Electrophoresis was carried out at $100 \mathrm{~V}$ for $2 \mathrm{~h}$ on an AmershamPharmacia Biotech (Uppsala, Sweden) power supplier unit ECPS3000/150. The stained bands were visualized with UV light (309 $\mathrm{nm}$ ) using a trans-illuminator and gels were recorded as digital TIFF images using a gel documentation system (UVI-Tech).

\section{Statistical analysis}

Data from patients infected with MRSA strains were saved in an EXCEL 5.0 program (Microsoft) and analyzed lately with version 6.04 of the Epi Info 6 software. Differences were considered significant at $p<0.05$.

\section{RESULTS}

Of the 18083 clinical specimens included in the present study, only $2764(15.3 \%)$ were positively cultured and $150(5.4 \%)$ were identified as $S$. aureus. The number of isolates and their frequency of isolation from each type of specimen are shown in Table 2. The distribution of isolates and MRSA strains according to specimen type and patient site are shown in Table 3. Out of the $150 \mathrm{~S}$. aureus isolates, 31 MRSA $(20.7 \%)$ were identified by the oxacillin agar screen test.

The majority of isolated MRSA was mainly from in-patients $(80.6 \%)$ while the remaining $(19.4 \%)$ were from specimens from outpatients. $\beta$ - 
lactamase production was high among the isolates, thus, $124(82.7 \%)$ out of the $150 \mathrm{~S}$. aureus isolates were $\beta$-lactamase positive isolates comprised $31 \mathrm{MRSA}$ and $93 \mathrm{MSSA}$ isolates. Thus, the rate of $\beta$-lactamase production among MRSA isolates was $98.4 \%$ and among MSSA was $78.6 \%$.

The susceptibility of the 150 isolates was determined for nine anti-staphylococcal chemotherapeutic agents including TMS, gentamicin, rifampicin, ciprofloxacin, mupirocin, vancomycin, teicoplanin, $\mathrm{Q} / \mathrm{D}$, and linezolid. The susceptibility results for individual drugs were interpreted according to CLSI criteria [19]. The breakpoints of susceptibility and resistance and the overall and differential susceptibility profiles of MRSA and MSSA isolates are shown in Table 4. The $\mathrm{MIC}_{50}$ and $\mathrm{MIC}_{90}$ for MRSA and MSSA are shown in Table 5 . The data reflect the remarkable differences between the two groups for gentamicin, TMS, and ciprofloxacin. However, rifampicin, mupirocin, vancomycin, and $Q / D$ demonstrated normal and high activity against both groups. The pattern of susceptibility was almost similar for linezolid, which showed relatively low activity.

The $S$. aureus isolates were tested genotypically using multiplex PCR for direct detection of femB and $m e c A$ genes. Figure 1 shows an agarose gel stained with ethidium bromide to demonstrate the results by the femB and mecA duplex PCR. It revealed the presence of $f e m B$ and $m e c A$ in all of the MRSA isolates. However, one isolate of MSSA have shown the presence of mecA gene having the potential to become MRSA in prospect. PCR product of $m e c A$ gene $310 \mathrm{bp}$ for the resistant isolates was applied on lane 3-8 which showed clear bands confirmed that, all the tested isolates were MRSA.

\section{DISCUSSION}

The present study was conducted to determine the prevalence of MRSA in clinical specimens recorded in Delta area through the studying of the clinical specimens received in routine bacteriology laboratory of the TUH over a limited

Table 1: Nucleotide sequences of multiplex PCR primers used for identification of MRSA

\begin{tabular}{lccc}
\hline $\begin{array}{l}\text { Name of } \\
\text { primer }\end{array}$ & $\begin{array}{c}\text { Sequence } \\
\mathbf{5}^{\prime}-3^{\prime}\end{array}$ & $\begin{array}{c}\text { Product } \\
\text { size bp }\end{array}$ & Reference \\
\hline mecA-F & GTA GAA ATG ACT GAA CGT CCG ATA A & $310 \mathrm{bp}$ & {$[21]$} \\
mecA-R & CCA ATT CCA CAT TGT TTC GGT CTA A & & \\
femB-F & TTA CAG AGT TAA CTG TTA CC & $651 \mathrm{bp}$ & {$[21]$} \\
$f e m B-\mathrm{R}$ & ATA CAA ATC CAG CAC GCT CT & & \\
\hline
\end{tabular}

Table 2: Specimen source, prevalence of $S$. aureus and distribution of MRSA in clinical specimens

\begin{tabular}{lcccc}
\hline Specimen & $\begin{array}{c}\text { No. of } \\
\text { specimens }\end{array}$ & $\begin{array}{c}\text { No. of } \\
\text { positive culture }\end{array}$ & $\begin{array}{c}\text { S. aureus isolates/per } \\
\text { positive specimens, } \\
\text { N (\%) }\end{array}$ & $\begin{array}{c}\text { MRSA per S. aureus } \\
\text { isolates, N (\%) }\end{array}$ \\
\hline Urine & 9611 & 869 & $3(0.3)$ & $1(33.3)$ \\
Wound discharge & 3879 & 941 & $98(10.4)$ & $21(21.4)$ \\
Blood & 1796 & 189 & $11(5.8)$ & $1(9.1)$ \\
Faeces & 1170 & 47 & $0(0)$ & $0(0)$ \\
Sputum & 543 & 153 & $3(2.0)$ & $1(33.3)$ \\
Aspirate & 309 & 134 & $7(5.2)$ & $1(14.3)$ \\
Body fluid & 277 & 24 & $2(9.1)$ & $0(0)$ \\
Genital swab & 197 & 196 & $0(0)$ & $0(0)$ \\
Tissue biopsies & 143 & 57 & $4(7.0)$ & $2(50.0)$ \\
Nasal swabs & 52 & 52 & $14(26.9)$ & $2(14.3)$ \\
Eye swab & 41 & 36 & $4(11.1)$ & $1(25.0)$ \\
Throat swab & 35 & 36 & $3(8.3)$ & $1(33.3)$ \\
Ear swab & 30 & 30 & $1(3.3)$ & $0(0)$ \\
Total & 18083 & $2764(15.3 \%)$ & $150(5.4)$ & $31(20.7)$ \\
\hline
\end{tabular}


Table 3: Distribution of MRSA in different clinical specimens

\begin{tabular}{|c|c|c|c|c|c|c|}
\hline \multirow[t]{3}{*}{ Specimen } & \multirow{3}{*}{$\begin{array}{l}\text { S. aureus } \\
\text { isolates } \\
\text { (N) }\end{array}$} & \multicolumn{2}{|c|}{ Isolates (N) } & \multirow{3}{*}{$\begin{array}{c}\text { MRSA } \\
\text { isolates, } \\
N(\%)\end{array}$} & \multicolumn{2}{|c|}{ MRSA isolates, $\mathbf{N}(\%)$} \\
\hline & & Outpatient & In-patients & & & \\
\hline & & & & & Outpatient & In-patients \\
\hline $\begin{array}{l}\text { Wound } \\
\text { discharge }\end{array}$ & 98 & 43 & 55 & $21(21.4)$ & $5(11.6)$ & $16(29.1)$ \\
\hline Nasal swabs & 14 & 3 & 11 & $2(14.3)$ & 0.0 & 2 (18.9) \\
\hline Blood & 11 & 0 & 11 & $1(9.1)$ & 0.0 & $1(9.1)$ \\
\hline Body aspirate & 7 & 1 & 6 & $1(14.3)$ & 0.0 & $1(16.7)$ \\
\hline Eye swabs & 4 & 3 & 1 & $1(25.0)$ & 0.0 & $1(100)$ \\
\hline Tissue biopsies & 4 & 0 & 4 & $2(50.0)$ & 0.0 & $2(50)$ \\
\hline Throat swabs & 3 & 2 & 1 & $1(33.3)$ & 0.0 & 1 (100) \\
\hline Urine & 3 & 2 & 1 & $1(33.3)$ & 0.0 & $1(100)$ \\
\hline Sputum & 3 & 0 & 3 & $1(33.3)$ & 1.(100) & 0.0 \\
\hline Body fluids & 2 & 1 & 1 & $0(0)$ & 0.0 & 0.0 \\
\hline Ear swabs & 1 & 1 & 0 & $0(0)$ & 0.0 & 0.0 \\
\hline Total & 150 & 56 & 94 & $31(20.7)$ & $6(10.7)$ & $25(26.6)$ \\
\hline
\end{tabular}

Table 4: Total and differential antibiotic susceptibility pattern of $S$. aureus isolates

\begin{tabular}{|c|c|c|c|c|c|c|c|c|c|}
\hline \multirow{2}{*}{$\begin{array}{l}\text { Antimicrobial } \\
\text { agent }\end{array}$} & \multicolumn{3}{|c|}{ MSSA $(n=119)$} & \multicolumn{3}{|c|}{ MRSA $(n=31)$} & \multicolumn{3}{|c|}{ Total $(n=150)$} \\
\hline & $\mathbf{S}$ & I & $\mathbf{R}$ & $\mathrm{S}$ & I & $\mathbf{R}$ & $\mathrm{S}$ & I & $\mathbf{R}$ \\
\hline Rifampicin & $116(97.5)$ & $0(0)$ & $3(2.5)$ & $24(77.4)$ & $0(0)$ & $7(22.6)$ & $140(93.3)$ & $0(0)$ & $10(6.7)$ \\
\hline Gentamicin & 116 (97.5) & $0(0)$ & $3(2.5)$ & $15(48.4)$ & $0(0)$ & $16(51.6)$ & $131(87.3)$ & $0(0)$ & 19 (12.7) \\
\hline TMS & 115 (96.6) & $1(0.8)$ & $3(2.5)$ & $12(38.7)$ & $1(3.2)$ & $18(58.1)$ & $127(84.7)$ & $2(1.3)$ & $21(14.0)$ \\
\hline Ciprofloxacin & $113(95.0)$ & $3(2.5)$ & $3(2.5)$ & $10(32.3)$ & $2(6.5)$ & $19(61.3)$ & $123(81.3)$ & $5(3.3)$ & $22(15.3)$ \\
\hline Mupirocin & 118 (99.2) & $1(0.8)$ & $0(0)$ & $30(96.8)$ & $1(3.2)$ & $0(0)$ & $148(98.7)$ & $2(1.3)$ & $0(0)$ \\
\hline Linezolid & $56(47.1)$ & $0(0)$ & $63(53.0)$ & $21(67.7)$ & $0(0)$ & $10(32.3)$ & 77 (51.3) & $0(0)$ & $73(48.7)$ \\
\hline Vancomycin & 119 (100) & $0(0)$ & $0(0)$ & $31(100)$ & $0(0)$ & $0(0)$ & $150(100)$ & $0(0)$ & $0(0)$ \\
\hline $\mathrm{Q} / \mathrm{D}$ & 118 (99.2) & $0(0)$ & $1(0.8)$ & $31(100)$ & $0(0)$ & $0(0)$ & 149 (99.3) & $0(0)$ & $1(0.7)$ \\
\hline Teicoplanin & $119(100)$ & $0(0)$ & $0(0)$ & $31(100)$ & $0(0)$ & $0(0)$ & $150(100)$ & $0(0)$ & $0(0)$ \\
\hline
\end{tabular}

$S=$ susceptibility; I = Intermediate; $R$ = resistance

Table 5: Distribution of $\mathrm{MIC}, \mathrm{MIC}_{50}, \mathrm{MIC}_{90}(\mu \mathrm{g} / \mathrm{ml})$ for $S$. aureus isolates to different antimicrobial agents

\begin{tabular}{lccccc}
\hline Antimicrobial agent & MIC range & \multicolumn{2}{c}{ MSSA $(\mathbf{n = 1 1 9 )}$} & \multicolumn{2}{c}{ MRSA $^{(\mathbf{n}=31)}$} \\
\cline { 3 - 6 } & $\boldsymbol{\mu g} / \mathbf{m l}$ & $\mathbf{M I C}_{\mathbf{5 0}}$ & $\mathbf{M I C}_{\mathbf{9 0}}$ & MIC $_{\mathbf{5 0}}$ & $\mathbf{M I C}_{\mathbf{9 0}}$ \\
\hline Gentamicin & $0.06-512$ & 0.25 & 1 & 64 & 256 \\
Rifampicin & $0.00125-64$ & 0.01 & 0.01 & 0.01 & 32 \\
TMS & $0.25-512$ & 1 & 4 & 128 & 512 \\
Ciprofloxacin & $0.06-64$ & 0.5 & 1 & 16 & 32 \\
Mupirocin & $0.03-64$ & 0.25 & 0.25 & 0.25 & 0.25 \\
Linezolide & $0.25-32$ & 4 & 4 & 2 & 4 \\
Vancomycin & $0.125-64$ & 1 & 2 & 1 & 2 \\
Q/D & $0.03-16$ & 0.25 & 1 & 0.5 & 1 \\
\hline
\end{tabular}

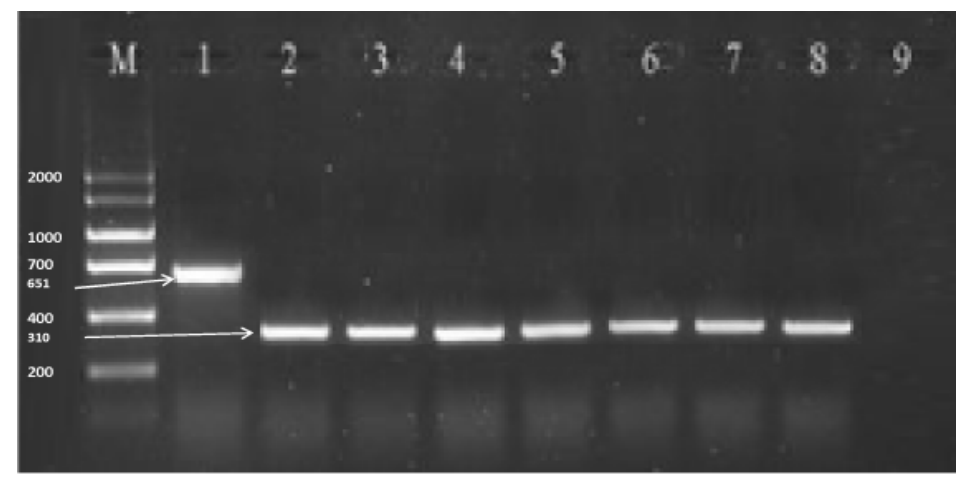

Figure 1: Agarose gel electrophoresis showing the PCR patterns of 651-bp and $310 \mathrm{bp}$ amplified genes of femB and $m e c A$ respectively for detection of $S$. aureus from clinical isolates. Lane 1: MSSA; lane 2: MRSA; lanes 3-8: MRSA strains; lane 9: blank; lanes M: marker 
period of 8 months from February to September. One hundred and fifty $S$. aureus isolates were recovered from 18083 specimens, representing $5.4 \%$ of all bacterial-positive cultures. Sixty five percent of $S$. aureus isolates were recovered from pus or wound discharge with isolation rate of $10.4 \%$ of such specimens. MRSA represented $21.4 \%$ of the $S$. aureus isolates as determined by the oxacillin agar plate screen. Though high, this figure is still lower than those reported in some studies from South Europe, USA and the Far East $[6,7,29]$.

Concerning Egypt, prevalence rates of MRSA among $S$. aureus isolates ranged from less than $17 \%(16.3 \%)$ in a University Hospital in Cairo [15], through $26.6-28 \%$ in two tertiary care hospitals in Mansoura and Cairo cities [13, 22] to as high as $61 \%$ in three hospitals in Cairo city, two are tertiary care hospitals and one public hospital [16]. Varying prevalence rates of MRSA were obtained from different hospitals in the same country and even different sites in the same hospital [23]. High percentage of $S$. aureus isolates $(82.7 \%)$ were $\beta$-lactamase producer with higher predominance among MRSA (98.4 $\%)$ compared with MSSA (78.6 \%). The MRSA prevalence was higher among the inpatients specimens $(62.6 \%)$ than those of outpatients (10.7\%). MRSA represented $20.5 \%$ of $S$. aureus pus isolates (195) and again with more predominance among those from inpatients (26.6 $\%)$ than from outpatients (12.8\%). This may be attributed to the presence of hospital related strains.

A panel of 9 commonly used anti-staphylococcal agents including two new drugs (Q/D and linezolid) and one used topically for control of nasal MRSA carrier (mupirocin) were tested for their efficacy against the isolates. As the case with $\beta$-lactamase production, the antibiotic susceptibility profiles reflected differences between the MRSA and MSSA isolates. While both groups showed high and comparable susceptibility to vancomycin, teicoplanin and mupirocin, MRSA were particularly more resistant to ciprofloxacin, TMS, gentamicin, and rifampicin. $\mathrm{MIC}_{50} \mathrm{~S}$ and $\mathrm{MIC}_{90} \mathrm{~S}$ demonstrated such differences between the MRSA and MSSA isolates for ciprofloxacin, TMS, and gentamicin. Although rifampicin showed similar $\mathrm{MIC}_{50} \mathrm{~S}$ values, different $\mathrm{MIC}_{90} \mathrm{~s}$ values were obtained for both groups with the resistant fractions representing $25 \%$ and only $1.7 \%$ of MRSA and MSSA, respectively. On the contrary, MSSA isolates were more resistant to linezolid that showed an overall modest activity. These susceptibility differences may reflect the frequent exposure of the MRSA clones resident in hospital environment due to the wide use of these drugs, as these clones are more likely to acquire resistance to many antibiotics [7].

Resistance to ciprofloxacin was reported to show considerable increase among MRSA after being used at large scale. For vancomycin, teicoplanin, $\mathrm{Q} / \mathrm{D}$ and mupirocin both groups of isolates demonstrated comparable susceptibility patterns. This is expected for the drug $Q / D$, which is a streptogramin antibiotic combination and for mupirocin which is not used therapeutically and used only for control of nasal carriage in some countries [5] but not in Egypt. The present results are in favor of proposing $Q / D$ as alternative therapy for MRSA infection [24]. The retained susceptibility to vancomycin and teicoplanin correlates with the restricted use of the drug and indicates its usefulness [25] and extending its role in being the mainstay in treatment of MRSA. On the other hand, linezolid which is one of a new class of antimicrobial chemotherapeutic agents, oxazilidinones, demonstrated low activity against MRSA and could not be proposed as an alternative therapy for MRSA infections, as previously reported [7]. Mupirocin has shown excellent anti-staphylococcal activity and proved effectiveness in eradication of MRSA carriage from patients and health care workers. However, reports of mupirocin resistance [26] undermine this role.

Accurate and rapid detection of methicillin resistance in $S$. aureus is imperative for the use of appropriate antimicrobial therapy and for the control of nosocomial spread of MRSA strains. Early diagnosis and appropriate treatment can significantly limit the duration and outcome of infection. The detection of $f e m B$ and $m e c A$ genes in $S$. aureus may also be helpful in explaining the severity of the infection. The PCR of femB and $m e c A$ genes were used as the gold standard for the evaluation of the traditional methods. The isolates were tested genotypically using multiplex PCR for direct detection of femB and mecA genes. In this study, $\operatorname{mec} A$ has been detected in all of the MRSA isolates and one isolate of MSSA showed the presence of mecA gene having the potential to become MRSA in prospect.

Several studies have reported the use of $m e c A$ as marker for MRSA detection and fem genes for recognition of $S$. aureus species. Positive correlation of phenotype with genotype tests were reported for MRSA isolates, which 
harboured mecA and femB genes [27]. Kobayashi et al reported that $m e c A$ was detected in $100 \%$ of MRSA, $16.7 \%$ of MSSA isolates [28]. In Egypt, only few studies have reported the use of femA along with $m e c A$ as molecular targets for identification of $S$. aureus and characterisation of MRSA [12,22] and there were no reports which specifically investigated the prognostic value of $f e m B$ gene for the detection of $S$. aureus.

\section{CONCLUSION}

This study demonstrates the relatively high prevalence of MRSA in $S$. aureus from the hospital specimens and high resistance rates among these strains to ciprofloxacin, TMS, gentamicin and rifampicin. High susceptibility rates were found to vancomycin, teicoplanin, $Q / D$ and mupirocin but unexpected modest activity was found for linezolid. Further, femB along with mecA appears the most accurate method for detection of MRSA and the mecA PCR in this study showed absolute positive correlation to MRSA phenotype.

\section{ACKNOWLEDGEMENT}

The Author extends his appreciation to the Deanship of Scientific Research at King Saud University for funding the work through the research group project No. RGP-VPP-202.

\section{REFERENCES}

1. Al-Jumaily E, Mohamed D, Khanaka H. Molecular epidemiology and Antibiotic susceptibility patterns of c1inical strains of methicillin resistant Staphylococcus aureus (MRSA) in Sulaimani city-Iraq. Glob Adv Res J Microbiol 2012; 6: 81-89.

2. World Health Organization (WHO). 2011 Public Health Importance of Antimicrobial Resistance. See: http://www.who.int/drugresistance/AMR_Importance/ en/index.html

3. Madani T, Al-Abdullah N, Al-Sanousi A, Ghabrah T, Bajunid $H$. Methicillin-resistant Staphylococcus aureus in two tertiary-care centers in Jeddah, Saudi Arabia. Infect Control Hosp Epidemiol 2002001; 14: 211-216.

4. Liu C, Bayer A, Cosgrove S, Chambers H. Clinical Practice Guidelines by the Infectious Diseases Society of America for the Treatment of MethicillinResistant Staphylococcus aureus Infections in Adults and Children. Clin Infect Dis 2011; 1-38.

5. Rehm S. Staphylococcus aureus: The new adventures of a legendary pathogen. Cleveland Clinic Journal of Medicine, 2008; 75: 177-192.
6. Johnson A. Methicillin-resistant Staphylococcus aureus: the European landscape J Antimicrob Chemother 2011; 66(Suppl 4): iv43-iv48.

7. Verhoef J, Beaujean D, Block H, Baars A, Meyler A, Van der Werken C. Dutch approach to methicillin-resistant Staphylococcus aureus. Eur J Clin Infect Dis 1999; 18: $461-466$

8. Hartman B, Tomasz A. Low-affinity penicillin-binding protein associated with beta-lactam resistance in Staphylococcus aureus. J Bacteriol 1984; 158: 513516.

9. Maes N, Magdalena J, Rottiers S, De Gheldre $Y$, Struelens MJ. Evaluation of a triplex PCR assay to discriminate Staphylococcus aureus from coagulasenegative staphylococci and to determine methicillin resistance from blood cultures. J Clin Microbiol 2002; 40: 1514-1517.

10. Gradelski E, Valera L, Aleksunes L, Bonner D, FungTomc J. Correlation between the genotype and phenotypic categorization of staphylococci based on the methicillin susceptibility and resistance. J Clin Microbiol 2001; 39: 2961-2963.

11. Hegde S, Shrader T. FemABX Family Members Are Novel Nonribosomal Peptidyltransferases and Important Pathogen-Specific Drug Targets. J Biol Chem, 2001; 10: 6998-7003.

12. El-Sharif $A$, Ashour $H$. Colonization and Infection in Intravenous and Inhalational Opiate Drug Abusers Community-Acquired Methicillin-Resistant Staphylococcus aureus (CA-MRSA). Exp Biol Med 2008; 233: 874-880.

13. Awadalla $H$, Khalil I, Bassim $H$, Ahmed M, Wahba $L$. Molecular typing of methicilin-resistant Staphylococcus aureus isolates at Ain Shams University Hospital, Egypt. Afr J Microbiol Res 2010; 4: 1639-1646.

14. Helal ZH, Gomaa FA, Radwan S. New Rapid Method for Differentiation of MRSA and SSA by PCR Restriction Analysis of 920 bp of Dnaj genePrime $J$ Microbiol Res 2012; 2(5): 141-146.

15. Shehab El-Din S, El-Shafey E, El-Hadidy M, Zaghloul H. Methicillin Resistant Staphylococcus aureus: A problem in the burns unit. Egypt $J$ Plast Reconstr Surg 2003; 27: 1-10.

16. Rushdy A, Salama M, Othman A. Detection of Methicillin/Oxacillin Resistant Staphylococcus aureus Isolated from Some Clinical Hospitals in Cairo Using Meca/Nuc Genes and Antibiotic Susceptibility Profile Int J Agri Biol 2007; 9: 800-806.

17. Mohanasoundaram K, Lalitha M. Comparisonof phenotypic versus genotypic methods in the detection of methicillin resistance in Staphylococcus aureus. Indian J Med Res 2008; 127: 78-84.

18. Kloos W, Lambe D. Manual of Clinical Microbiology, 5th ed. Washington, D.C.: American Society for Microbiology, 1991 pp 222- 237.

19. Clinical and Laboratory Standards Institute (CLSI). Performance standards for antimi-crobial

Trop J Pharm Res, August 2014; 13(8): 1245 
susceptibility testing: seventeenth informational supplement [document M100-S17]. Wayne, PA: CLSI, 2007.

20. Ausubel FM, Brent R, Kingston R, Moore DE, Seidman, Smith JA., Strunt K. Short Protocols in Molecular Biology, 4th edn. John Wiley and Sons Inc. 1999, New York.

21. Jonas D, Speck M, Daschner F, Grundmann H. Rapid PCR-Based Identification of Methicillin-Resistant Staphylococcus aureus from screening swabs. J Clin Microbiol 2002; 40: 1821-1823.

22. Gad Y, Talaat N. Methecillin Resistant Staphylococcal aureus (MRSA) isolates from a hepatology intensive care unit in Egypt: A silent killer. E\&C Hepatol 2012; 8: $35-44$

23. Voss A, Doebbeling $B$. The worldwide prevalence of methicillin-resistant Staphylococcus aureus. Intern J Antimicrob Agents 1995; 5: 101-106.

24. Low $D$, Nadler H. A review of in vitro antibacterial activity of quinupristin/dalfopristin against methicillin- susceptible and resistant Staphylococcus aureus. J Antimicrob Chemother 1997; 39 (Suppl. A), 53-58.

25. Fraise A. Guidelines for the control of methicillin-resistant Staphylococcus aureus. J Antimicrob Chemother 1998; 42: 287-289.

26. Marple R, Speller D, Cookson B. Prevalence of mupirocin resistance in Staphylococcus aureus. J Hosp Infect 1995; 29: 153-154.

27. Al-Talib H, Chan $Y$, Alyaa A, Al-Jashamy $K$, Ravichandran M. A Pentaplex PCR Assay for the Detection of Methicillin-Resistant Staphylococcus aureus and Panton-Valentine Leucocidin BMC Microbiol 2009; 9: 113.

28. Kobayashi N, Wu H, Kojima K, Yagihashi A, Kurokawa I. Detection of mecA, femA, and femB Genes in Clinical Strains of Staphylococci Using Polymerase Chain Reaction Epidem Infect 1994; 113: 259-266.

29. Gutierrez K, Halpern MS, Sarnquist C, Soni S, Arroyo AC, Maldonado Y. Staphylococcal infections in children, california, USA, 1985-2009. Emerg Infect Dis. 2013; 19: 10-20. 